\title{
Dificultades, logros y desafíos para el 2021
}

Difficulties, accomplishments, and challenges for 2021

El comienzo de un nuevo año para Archivos nos lleva a reflexionar sobre los logros y las dificultades del año 2020 y los desafíos para el 2021.

Habría que empezar por las dificultades, porque fueron excepcionalmente grandes. La pandemia por COVID-19 cambió en forma radical y brusca nuestras vidas, no solo como profesionales sino en todos los aspectos.

Como editores tuvimos que aprender una nueva forma de trabajo a distancia. Archivos no se podía detener y, con la tecnología en información y comunicación disponibles, y la mayor o menor capacitación en su uso, seguimos adelante.

Hay que destacar los aspectos positivos de esta situación. Menos tiempo perdido en desplazarse entre los lugares de trabajo, más tiempo para la familia, mayor flexibilidad horaria laboral. En esto se nota el compromiso de cada uno de los miembros del equipo editorial con su tarea. Sin horarios estrictos, cada uno aportó todo el tiempo necesario para estar al día y mantener el nivel de calidad editorial y científica de Archivos.

Otro aspecto positivo fue la respuesta de los grupos de trabajo de la Sociedad Argentina de Pediatría ante el pedido de la Comisión Directiva de iluminar desde su especialidad, los nuevos conocimientos teóricos sobre esta pandemia y los aspectos prácticos para el ejercicio profesional. Recibimos en poco tiempo, gran cantidad de artículos que, después de un procesamiento editorial abreviado, pasaron a constituir el Suplemento COVID-19, publicado en octubre del año pasado. ${ }^{1}$

También tuvimos que enfrentar un problema compartido por todas las revistas científicas: la sensación de urgencia por publicar novedades sobre el tema. El rigor en la evaluación de los trabajos recibidos no debe someterse a la urgencia de divulgar experiencias. El conocimiento científico tiene bases metodológicas que definen su calidad. Sin ellas, solo se llega a la publicación sin filtros y, a veces, de conceptos erróneos. ${ }^{2}$ Sin duda tuvimos especial cuidado en acelerar el proceso de revisión en aquellos trabajos con calidad científica para ponerlos al alcance de la comunidad pediátrica.

Desde Archivos se llamó la atención sobre los efectos secundarios no deseados del manejo de la pandemia. Disminución de los controles en salud del niño sano, demora en la atención de otras patologías, postergación de cirugías programadas, seguimiento irregular de los niños con enfermedades crónicas, menor cobertura del calendario de vacunaciones. . $^{3,4}$

La falta de escolaridad no se limita a la pérdida de la instrucción. La escuela es más que eso; es socialización, contención, detección de condiciones de salud o del entorno familiar que merecen atención. La escolaridad a distancia llevó a los niños a un mayor tiempo frente a las pantallas con los potenciales riesgos que eso implica (sedentarismo, trastornos visuales). ${ }^{5}$

En todos estos problemas la inequidad en el acceso a los recursos agrava los perjuicios. La educación a distancia requiere de tecnología, de acompañamiento familiar que no todos los niños tienen. El empobrecimiento de la comunidad por la pérdida de fuentes de trabajo los hace más vulnerables todavía. ${ }^{6}$ Hemos adquirido mejores hábitos de higiene y eso teóricamente redunda en menores posibilidades de infecciones respiratorias, pero no en todos lados hay acceso al agua potable.

La pandemia transcurre en este escenario difícil. Nos encontró poco preparados para enfrentarla. Ahora viene el desafío de este año 2021. ¿Qué podemos hacer para aportar soluciones desde donde nos toca actuar?

Deberíamos facilitar el acceso al sistema de salud de quienes lo necesitan. Eso requiere de protocolos de atención para proteger a los niños y a los profesionales. Podemos mejorar la consulta a distancia, desarrollar formas de contacto con los pacientes para hacer un seguimiento de los cuidados que necesitan. Debemos alertar a las familias sobre la necesidad de un equilibrio entre el tiempo que los niños pasan ante las pantallas y el tiempo recreativo, al aire libre, con actividad física. A otras instancias corresponde mejorar las condiciones de vida de las comunidades vulnerables. 
Los grandes acontecimientos cambian brusca y definitivamente nuestras vidas y ponen a prueba nuestra resiliencia, la capacidad de adaptarnos a modos nuevos, de tener otras metas, sin demasiadas certezas, pero con el convencimiento que es mejor comenzar a construir ese futuro.

\section{Dra. Norma Rossato} Editora asociada

http: / / dx.doi.org/10.5546/ aap.2021.2

Texto completo en inglés:

http: / / dx.doi.org/10.5546/ aap.2021.eng.2

Cómo citar: Rossato N. Dificultades, logros y desafíos para el 2021. Arch Argent Pediatr 2021;119(1):2-3.

\section{REFERENCIAS}

1. Suplemento COVID-19. Arch Argent Pediatr. Octubre 2020:c1-c144.

2. Spec A, Schwartz IS. Balancing Scientific Rigor With Urgency in the Coronavirus Disease 2019 Pandemic. Open Forum Infect Dis. 2020;7(8):ofaa304.

3. TornerN.Collateraleffects ofCovid-19 pandemicemergency response on worldwide immunizations. Vacunas. 2020;21(2):73-5.

4. Rodríguez MS. COVID-19. La pandemia y los chicos. Arch Argent Pediatr. 2020;118(5):302-3.

5. Wong CW, Tsai A, Jonas JB, Ohno-Matsui K, et al. Digital Screen TimeDuring COVID-19Pandemic: Risk for a Further MyopiaBoom? Am J Ophthalmol.2020;S0002-9394(20)303925. [En prensa].

6. Vain N, Cardigni G, Capra D. La pandemia, el futuro en la salud de los niños y el desarrollo de la pediatría. Arch Argent Pediatr. 2020;118(6):378-80.

\section{Publicaciones Informa}

\section{MANUAL DE EMERGENCIAS Y CUIDADOS CRITICOS EN PEDIATRIA}

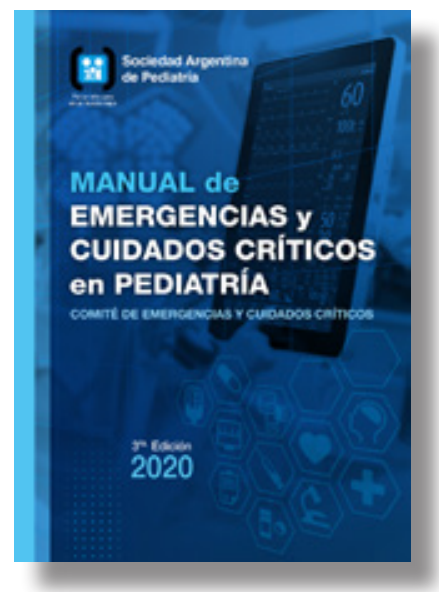

Esta 3ra. Edición del Manual de Emergencias y Cuidados Críticos en Pediatría, cuenta con 72 capítulos y más de 1100 páginas. Brinda información útil para hacer frente a los desafíos que se presentan en la práctica habitual. Se actualizaron capítulos anteriores y desarrollaron nuevos temas, principalmente para la nueva especialidad emergentología pediátrica.

El aporte de 166 autores del país y del exterior permitió incorporar nuevos puntos de vista. El resultado es el consenso de numerosas perspectivas cuyo objetivo final es que los lectores puedan incorporar aquellas prácticas que amplíen su capacidad para cuidar a niños con enfermedades graves, agudas y complejas.

Esperamos que disfrute de la lectura y lo motive aún más a desarrollar su profesión. 